University of Nebraska - Lincoln

DigitalCommons@University of Nebraska - Lincoln

10-1971

\title{
Insect Flagellates from Feces and Gut Contents of Four Genera of Lizards
}

Norman R. Dollahon

Villanova University, norman.dollahon@villanova.edu

John J. Janovy Jr.

University of Nebraska - Lincoln, jjanovy1@unl.edu

Follow this and additional works at: https://digitalcommons.unl.edu/bioscijanovy

Part of the Parasitology Commons

Dollahon, Norman R. and Janovy, John J. Jr., "Insect Flagellates from Feces and Gut Contents of Four Genera of Lizards" (1971). John Janovy Publications. 29.

https://digitalcommons.unl.edu/bioscijanovy/29

This Article is brought to you for free and open access by the Papers in the Biological Sciences at DigitalCommons@University of Nebraska - Lincoln. It has been accepted for inclusion in John Janovy Publications by an authorized administrator of DigitalCommons@University of Nebraska - Lincoln. 


\section{Insect Flagellates from Feces and Gut Contents of Four Genera of Lizards}

During investigations of experimental leishmaniasis in American lizards, insect flagellates of at least two genera were isolated from freshly deposited fecal material and gut contents of two genera of Central American lizards (Basilicus and Ameiva). Flagellates were not observable directly in the feces of the lizards, but were isolated in Mansour's Medium (5 g Bacto-beef infused in $200 \mathrm{ml}$ distilled $\mathrm{H}_{2} \mathrm{O}$; filtered into a flask containing $4 \mathrm{~g}$ neopeptone, $1.6 \mathrm{~g} \mathrm{NaCl}, 0.04 \mathrm{~g} \mathrm{KCl}, 0.04 \mathrm{~g} \mathrm{CaCl}_{2}, 0.06 \mathrm{~g}$ $\mathrm{KH}_{2} \mathrm{PO}_{4}$, and $0.5 \mathrm{~g}$ glucose; heated to boiling; neutralized, filtered, and autoclaved; with hemolyzed rabbit blood added to a final concentration of $10 \%$ ) with 700 units of penicillin and $700 \mu \mathrm{g}$ of streptomycin per milliliter. Thicker flagella, and a more rapid movement and translocation, easily distinguished the flagellates from Leishmania promastigotes. On one stained slide prepared from a 24 -hr isolate of Ameiva feces, approximately $25 \%$ of the flagellates had postnuclear kinetoplasts, $25 \%$ had paranuclear kinetoplasts, and the remaining $50 \%$ were forms with kinetoplasts anterior to the nucleus. Generally, the forms with kinetoplasts anterior to the nucleus were by far the predominant type; and the majority of these possessed a broad reservoir and most closely resembled Crithidia. The insect flagellates survived in $1 \%$ proteose-peptone-glucose medium for up to three transfers, whereas the leishmanias did not.

Examination of lizard cages revealed dipteran larvae and pupae in the water dishes. Both stages contained large numbers of typanosomatid gut flagellates (Figure $1 \mathrm{a}-\mathrm{e}$ ), and flagellates from the fly larvae were subsequently isolated in Mansour's Medium (Fig. $1 j-m)$. The flagellates in the flies were primarily promastigote, but a number of them had an extremely wide reservoir and closely resembled choanomastigotes except for their greater length. Occasionally, very small flagellates were observed which more closely resembled Crithidia. The cultural isolates contained a small number of forms with postnuclear kinetoplasts in addition to typical promastigotes and choanomastigotes. The flies were probably infected with a Crithidia and a Leptomonas or a
Herpetomonas. The fly was identified as Megaselia scalaris (family Phoridae) by Dr. William Robinson (Cooperative Extension Service, Virginia Polytechnic Institute). We have attempted to clonally isolate a flagellate from the fly as suggested by Wallace (1970, J. Parasit. 56(4) Sect. II: 358-359), but variability of the forms in culture indicates that we have possibly not yet succeeded.

Experiments were conducted to determine if the flagellates from the lizard feces and gut contents were the same as those in the flies. Twelve locally captured Cnemidophorus sexlineatus were placed in closed plastic boxes. Fecal material was collected and examined directly as well as being placed in culture medium. All examinations and cultures were negative for trypanosomatids. Five of the $C$. sexlineatus were fed meal worms (Tenebrio) and served as controls. Each of the remaining seven was fed an infected larva from Megaselia cultures maintained on a cornmeal-molasses-agar medium. The lizards were killed over a period of 17 days, the guts were removed, and portions were placed in culture. Cultures were made from several organs and heart blood, but all proved negative. Gut segment or gut content cultures (obtained by catheter) from three of the seven experimental animals (one examined at 3 days, one at 6 days, and one at 16 days after the initial feeding) were positive. Only one of the lizards (16 days) was fed larvae after the initial feeding. It had been fed larvae 24 and $48 \mathrm{hr}$ prior to the gut probe which gave a positive culture. When killed, 3 days after the final feeding, the animal was negative by gut segment culture. All control cultures were negative, and attempts to observe the flagellates in gut contents of control animals failed.

Nine newly arrived Anolis carolinensis, obtained from E. D. Steinhilber and Co., Inc., were placed in closed plastic boxes. Cultures inoculated with material removed from the lizards' guts by catheter were negative. Four control animals were fed meal worms while the five experimentals were fed infected, wild Megaselia larvae obtained from guinea pig litter pans. These wild larvae appeared to be 
more heavily infected than those in cornmealmolasses-agar medium, and it was assumed that more heavily infected larvae would allow direct observation of the flagellates in the feces. All fecal pellets deposited by the experimental animals in the next 3 days were positive for flagellates. Insect larval remains were visible; associated with these were numerous flagellates. Stained slides revealed these to be similar to those isolated from the infected larvae. A series of stages from elongate forms to rounded bodies were present in the feces. Figure $1 \mathrm{f}-\mathrm{i}$ represents some of the forms seen. Many of these forms had wide reservoirs, and it was apparent that some of these flagellates were of the genus Crithidia. Some individuals with postnuclear kinetoplasts were observed in such preparations. Some of the lizards were also infected with Proteromonas. None of the control animals deposited feces containing insect flagellates. One experimental animal was dissected; the gut was removed and cut into sections. Cloacal contents and epithelial smears contained Proteromonas. Wet mounts of intestinal contents from just anterior to the cloaca had large numbers of the insect flagellates, and Proteromonas.

Due to problems involved in identification of these trypanosomatid flagellates, we sent Dr. William Hanson (College of Veterinary Medicine, The University of Georgia) slides of flagellates isolated from fecal material, slides of flagellates from larval guts, and slides of fly flagellates isolated in Mansour's Medium. Dr. Hanson (pers. comm.) felt that forms isolated from lizard feces most closely resembled Crithidia due to their truncate anterior end, although some were a bit long. Slides prepared from the fly larvae he felt showed some choanomastigotes, as well as promastigotes which could be either Leptomonas or Herpetomonas. The isolated fly flagellates he identified as being primarily Crithidia, but associated with these were promastigotes which could have been Leptomonas or Herpetomonas. Finally, he reported finding a few forms with postnuclear kinetoplasts on all the slides, but he did not know of what relative significance they might be since they were few in number on the supplied slides. Dr. Hanson suggested that the Crithidia, while rare in the fly, might

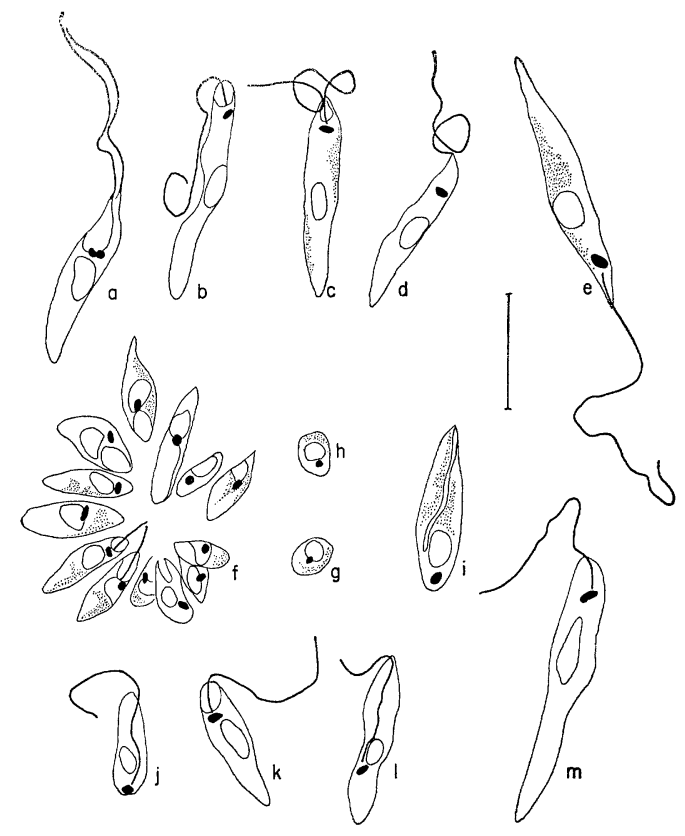

Figure 1. Camera lucida drawings of flagellates from Megaselia scalaris larval gut (a-e), Anolis carolinensis feces ( $\mathrm{f}-\mathrm{i})$, and culture isolates from larvae $(\mathrm{j}-\mathrm{m})$. Bar is $10 \mu$.

outgrow the other forms to become dominant in the cultures.

Zimmerman and Brown (1952, Proc. Okla. Acad. Sci. 33: 103-111) reported finding heavy Leptomonas infections in five genera of Oklahoma lizards, including Cnemidophorus. We have had the opportunity to review some of their slide material, but we have not been able to satisfactorily demonstrate the flagellates. Nonetheless, we have shown that such infections might exist in lizards were they feeding on appropriate flagellate-bearing insects.

Bayon (1915, Tr. Roy. Soc. S. Africa 5: 61-63) described flagellates which he ascribed to the genus Herpetomonas, from gut smears of African chameleons (Chamaeleon pumilus). $\mathrm{He}$ mentioned the similarity of these forms in Scatophaga hottentota, and suggested that it would not be impossible for the lizards to become infected by swallowing flies. Wenyon (1920, Parasitology 12: 350-365), in discussing a similar flagellate in Chamaeleon vulgaris, named the organism Leishmania chamaeleonis, and he was able to infect Musca domestica with 
these flagellates. In an apparent rebuttal, Bayon (1926, Parasitology 18: 361-362) named the flagellates, in C. pumilus, Herpetomonas mansoni. He mentioned the presence of similar organisms in other species of chameleons, and again made comparisons with insect flagellates.

Frenkel (1941, Indian J. Med. Res. 29: 811812 ) transmitted L. chamaeleonis to uninfected chameleons by oral and anal introduction of feces, and found what he felt were intracellular amastigotes in the gut epithelial cells of one lizard. Drawings of these forms are not convincing. Even if the forms were engulfed flagellates, the significance must be questioned. It is possible that any recently phagocytized flagellate of this type would show such a form. In a brief note Vickerman (1965, Tr. Roy. Soc. Trop. Med. Hyg. 59: 372) discussed isolating flagellates from Chamaeleon senegalensis using NNN medium or peptone-liver broth. The flagellates were described as having leptomonad, crithidial, and herpetomonad stages which Vickerman felt were indicative of Herpetomonas, but which probably were indicative of a mixed infection of insect flagellates. He found that the flagellates could temporarily infect blow-flies (Calliphora). Apparently Vickerman was not aware of Frenkel's work, but this should in no way make his arguments less valid.

Neither Heisch (1958, Ann. Trop. Med. Parasit. 52: 68-71) nor Adler (1964, Adv. Parasit. 2: 35-96) mentioned Bayon's (loc. cit.) flagellates as leishmanias, even though Wenyon (1926, Protozoology, William Wood and Co., New York) would have considered them as such without evidence of an intracellular amastigote form. Such forms have not been reported for Leishmania hoogstraali or L. adleri in the lizards.

In regard to our findings, it is difficult to accept certain references to gut involvement for lizard leishmanias. Leger (1918, Compt. Rend. Soc. Biol., Paris 81: 772-774) described a flagellate in stained blood smears of an Anolis from Martinique, and mentioned the similarity of this to that of a gut Leptomonas in the same lizard. Adler (loc. cit.) placed emphasis on this organism ("Leishmania henrici") as a transitional phase from an intestinal to a blood parasite, yet Leger clearly stated his inability to demonstrate a relationship between the two forms.

Heisch (loc. cit.) stated that Leishmania tarentolae can be found in the blood, organs, and gut; but he gave no reference for the statement. Wenyon (loc. cit.) mentioned the possibility of gut involvement, giving credit to Franchini (1921, Soc. Path. Exot., Paris 14: 641-645) who had indicated that flagellates do occur in the gut of some Tarentola mauritanica. Franchini also demonstrated a Leishmania and gut flagellate in Chalcides ocellata and suggested he had found the same flagellate in the guts of two muscoid larvae. This type of evidence is probably not sufficient to indicate a relationship between gut and blood flagellates. In addition, Strong (1924, Am. J. Trop. Med. 4: 345-385) found flagellates in the gut of a South American Cnemidophorus (C. lemniscatus) which had fed on naturally infected Chariestrus cuspidatus (Coreidae: Hemiptera), and claimed that the lizard flagellates were morphologically identical to those in the bugs. The experiments were uncontrolled, however, and did not show that a single flagellate was involved. Nevertheless, his studies in part may represent a natural case of what we have observed in the laboratory.

It appears to us that some of the conclusions regarding the biology of certain flagellates described as reptilian leishmanias must be accepted with caution. Insect flagellates do persist in the lizard intestine for several days, and it is entirely possibly that some reptilian "leishmanias," particularly those described with gut involvement, such as Leishmania henrici, may actually be insect flagellates.

Norman R. Dollahon and John Janovy, Jr., Department of Zoology, University of Nebraska, Lincoln, Nebraska 68508 